\title{
Facilitating Mentoring Relationships: The Case for New Technology
}

\author{
Pamela Kalbfleisch and Valina K. Eckley \\ University of Wyoming, Laramie, WY, USA
}

\author{
PamelaK@uwyo.edu
}

\begin{abstract}
This paper describes a research project that analyzes how new technology can facilitate mentoring relationships. The specific new technology assessed in this research is the Internet. This is a particularly useful medium for communication in mentoring relationships because it expands the number and variety of mentoring relationships that can be facilitated, and it expands the time and space available for these relationships. This research supports the mentoring enactment theory developed by Kalbfleisch (2002) and expands our knowledge of how the Internet can play an influential role in the development and maintenance of mentoring relationships.
\end{abstract}

\section{Introduction}

Research on new technology has established that people use the Internet to seek companionship (Wolak, Mitchell, \& Finkelhor, 2002), develop friendships (Adams-Price \& Chandler, 2000), and kindle romance (Merkle \& Richardson, 2000). The Internet has the potential to be a treasured resource in homogenous societies, organizations, and regions, where me mbers of under-represented populations can use the Internet as a touchstone to put them in contact with similar others. The Internet is a great equalizer, spanning the dimensions of time and space.

The study presented in this article examines the use of the Internet in facilitating mentoring relationships. Mentoring relationships have been found to be beneficial for both the mentor and the protégé (Kalbfleisch \& Davies, 1993). Mentors, or more advanced members of a group or organization, provide advice and assistance to less advanced members of the group or organization. Mentors benefit in achieving advanced social status and return aid from the protégés themselves. Protégés, or less advanced members of a group or organization, are helped by mentors. Protégés benefit greatly from this additional help, learning skills quicker than others, advancing quicker up the organizational ladder, earning higher salaries, learning unwritten rules of conduct, integrating into networks, having an advocate, and more quickly being an integrated member of a group or organization who is in the know.

In 2002, Kalbfleisch advanced an enactment theory of mentoring relationships that focused on the development of these relationships and the communication strategies that facilitate and maintain these relationships. One of the propositions of the Kalbfleisch theory is that asking someone to be a mentor is not as likely to be as successful a communication strategy for initiating a mentoring relationship as is for a

Material published as part of these proceedings, either on-line or in print, is copyrighted by Informing Science. Permission to make digital or paper copy of part or all of these works for personal or classroom use is granted without fee provided that the copies are not made or distributed for profit or commercial advantage AND that copies 1) bear this notice in full and 2) give the full citation on the first page. It is permissible to abstract these works so long as credit is given. To copy in all other cases or to republish or to post on a server or to redistribute to lists requires specific permission from the publisher at Publisher@InformingScience.org person desiring mentoring to first develop a relationship with a potential mentor, and then gradually work into a helping relationship.

Parker (in press), following up on this proposition of the Kalbfleisch theory in her essay on empowering black women in organizations, noted that this strategy may be difficult for black women to enact. Specifically she points out that if black 


\section{Facilitating Mentoring Relationships}

women have trouble developing a relationship with members of predominately white organizations then they will not be able to use this strategy to develop mentoring relationships.

If one strategy for initiating mentoring relationships is to pair members of similar groups together (Kalbfleisch, 2000) for mentoring, then this creates a special challenge for members of underrepresented groups to find mentors in the majority population. The Internet may offer help for these underrepresented group members.

First, the Internet expands the number of potential mentors in an organization. With mentors in characteristically short supply (Kalbfleisch, 1997); the Internet expands the number of potential mentors beyond the constraints of a group, organization, or region. Secondly, with reduced nonverbal cue availability, mentoring relationships may be easier to develop among diverse online groups than in face-toface interactions where nonverbal cues may override the desire to give and receive mentoring. In other words, people may be hindered by noticing superficial differences in face-to-face interactions that may not be quite so obvious in on line interactions. Thirdly, one issue in mentors' willingness to mentor or not is the time commitment that a mentoring relationship may take. An online mentoring relationship expands the time continuum to allow for mentoring on the mentors' schedule and convenience. No longer bound to meeting times, lunches, and appointments, the mentor can log on at will to help another.

There is a growing body of interpersonal literature into computer mediated communication (CMC). One of the major concerns asked in this literature is if relationships formed in a CMC environment truly be considered interpersonal, due to the lack of interpersonal cues. Answering this question, Walther and Burgoon (1992) found that interpersonal relationships can form in a CMC environment over time. Expanding from this research, Walther (1993) found that as the amount of messages transmitted in a CMC environment increases over time, impressions were developed. Also, research has shown that as the number of message s increase, the number of questions in those messages also increase (Pratt $\&$ Wiseman, 1999). These findings support the assumption that relationships can in fact develop through CMC. In fact, these relationship developed via text messages may affect one's perception of the other in the relationship. For example Walther, Slovacek, and Tidwell (2001) found that social attraction in a CMC environment increased if a picture is sent early on in a relationship. However, if a picture is sent after the relationship has already been developed, then the picture has little effect on social attraction. This finding provides further evidence that impressions of relationships do develop within a CMC environment, and that these impressions are strong. If a picture is sent after these impressions have already been developed, then it may have effect on the initial impressions (e.g. if the picture was not similar to one's initial impression, then it may negatively affect the relationship). From this short review of literature, it can be suggested that relationships can form on the Internet. Therefore, the next concern for researchers is to try to understand how specific types of relationships can develop on the Internet.

Expanding from this basic work of interpersonal relationships in a CMC environment, Wright (1999; 2000) has done a number of studies looking into social support in the CMC environment. He has found that those who are higher users of the Internet tend to be more satisfied with the levels of social support available on the Internet. He also found that higher Internet users have larger companion networks (Wright, 2000). More specifically, he has found that satisfaction of this social support inversely correlates with one's level of stress (Wright, 1999). This finding suggests that relationships developed through CMC can have benefits to one's personal lifestyle. Not only are CMC relationships real, but they may have effects similar to face-to-face relationships. Although, more research is needed to support this claim, looking at one specific type of relationship, that of social support has shown a positive benefit. Therefore looking at other types of online relationships may provide further insights into the advantages of relationships in a CMC environment.

Despite this growing body of research into the CMC social support there has never been a study of how specifically mentoring relationships can be formed and maintained in a CMC environment. However, 
there are a considerable number of advantages for online mentoring relationships have been suggested. These advantages include: access times are at the mentor's or protégé's discretion, geographical locations is no longer a consideration, and an increased social network with those one would normally not come into contact with (Knouse, 2001). Online mentoring may also have advantages for women and minorities, who often find it difficult to establish mentoring relationships in a face-to-face setting (Kalbfleisch 2002).

In our study we assess two propositions of the Kalbfleisch (2002) theory of enactment in mentoring relationships by analyzing the electronic communication between paired mentors and their protégés. Specifically we examine messages indicative of two of the theory's propositions:

Proposition 6: Protégés will be more likely than mentors to direct their conversational goals and communication strategies toward initiating, maintaining, and repairing their mentoring relationship. (Kalbfleisch, 2002, p. 67).

Proposition 8: Female protégés will be more likely than male protégés to direct their conversational goals and communication strategies toward initiating, maintaining, and repairing their relationship with their mentor. (Kalbfleisch, 2002, p. 68)

The research plan and design are as follows: 1) Interactions between paired mentors and protégés via electronic mail are captured, 2) the content and sequence of the messages are coded, and 3) messages are analyzed for relationship facilitation and maintenance strategies.

\section{Method}

\section{Participants}

The participants for the study were drawn from the graduate and undergraduate population at a university located in the Rocky Mountains of the United States of America. The participants were drawn from the graduate and undergraduate students enrolled in upper level and graduate seminar classes. The participants were offered extra credit as an incentive for their participation. A total of four males and six females ages 21 to 36 participated in the study. The graduate students were assigned to be the mentors for the study, while the undergraduates were assigned to be the protégés. Each mentor was randomly assigned to a protégé. In total, five mentor/protégé groups were created. In total, these groups consisted of one male mentor/male protégé group, two female mentor/female protégé groups, one female mentor/male protégé group and one male mentor/female protégé group.

Email was the primary means for the researchers to communicate to the participants about the study. The participants were emailed the web address for a private web forum that they would use to participate in the study. Each mentor/protégé group was assigned a specific web address to which only they had access. Finally, the participants were assigned pseudo names to use in the study in order to protect their confidentiality. They were also continuously asked throughout the course of the study to protect their anonymity. Each of the participants elected to maintain their anonymity throughout the study.

\section{Instrument}

The instrument through which the participants built their relationships was through Internet forum discussion groups. Forum discussion groups were chose due to their low cost of efficiency and their relatively ease of use and setup. Also, these discussion forum groups can be accessed at any time from anywhere on the web. This gave the participants the opportunity to participate in the study at their own leisure. Finally, the actual communication process in a forum discussion was automatically dated, time stamped, and recorded in the order that the postings were made. Therefore the transcripts of the communication itself were created by the computer as the participants communicated with each other. 


\section{Facilitating Mentoring Relationships}

Each mentor/protégé group was assigned to their own personal discussion forum. The names of the directories where each discussion group were located were randomly assigned in order to protect the confidentiality of one group from the other groups. Aside from the name, each of the discussion groups was exactly the same from each other. After the initial discussion group was created, it was simply copied and pasted inside the web server in order to create multiple forum discussion groups. The copies of the directories were then renamed names from foreign language dictionaries. Then the HTML code for all web page files for each group was checked to make sure that all the refe rences and links, including the image files, remained within the specific group. This had two purposes. First, it allowed each forum discussion group to act as separate entities from each other. This was necessary, so that if one of the forum discussion groups became corrupted, it wouldn't affect the system as a whole. Secondly, this protected the confidentiality of each individual forum discussion group. If a participant were to view the source code of their forum discussion group page, they would not be able to view the names of the other forum discussion groups. However, this would not be the case if the discussion groups referenced files from each other. Therefore it was incredibly important to set up every aspect of the discussion groups to run as separate entities from each other.

The actual web page was designed using a two frame system. The top frame consisted of the topics of the previous conversation threads. The bottom, larger frame contained given specific instructions pertaining to the experiment, and the contact information of the researchers in case the participant had any further questions. They were also given a reminder to protect their anonymity during the course of the study. Finally, they were thanked for their participation in the study. On this page there contained a link to the posting page, where they would be allowed to post to the discussion. On the posting page, the participants were given a communication directive designed to facilitate their conversations into a mentoring relationship. The directives were also designed to give the participant something to do during the study. Once each participant (the mentor and the protégé) fulfilled each communication directive, a new communication directive was given to the participants. An email was then sent to the participants informing them that a new communication directive had been set up, and that they should return to their webpage. The participants went through a total of 9 different communication directives (see Table1). After the participants finished all 9 communication directives, the link to the posting page was then removed, and the name of the posting page was changed on the web server. This would then prevent the participants from continuing posting to the website after the study was over. Afterwards, the participants received a final email thanking them for their participation in the study. Once the final group of participants finished their last communication directive, the entire system of the entire forum discussion group webpage network was backed up on both a zip disk and a CD-Rom.

\section{Table 1: Communication Directives}

\section{For the Mentor:}

A. Describe what you feel you can bring to an online conversational relationship. Describe what you would like to achieve in an online mentoring relationship.

B. Respond to your conversational partner's description of what your partner is bringing to this relationship and what your partner would like to achieve.

C. Describe a specific academic or career goal that you have and how you are planning to achieve this goal.

D. Respond to your conversational partner's description of academic and career goals and methods of achieving these goals.

E. Describe a frustrating experience that you have had at the university and how you could help your conversational partner avoid a similar situation. 
F. Respond to your conversational partner's request for advice.

G. Describe what you feel are the costs and the rewards of a college education.

H. Based on the previous conversations you have had with your partner, provide any advice that you believe would be helpful to your partner.

I. Respond to your conversational partner's request for advice.

\section{For the Protégé:}

A. Describe what you feel you can bring to an online conversational relationship. Describe what you would like to achieve in an online mentoring relationship.

B. Respond to your conversational partner's description of what your partner is bringing to this relationships and what your partner would like to achieve.

C. Describe a specific academic or career goal that you have and how you are planning to achieve this goal

D. Respond to your conversational partner's description of academic and career goals and methods of achieving these goals.

E. Respond to your conversational partner's experience and suggestions.

F. Describe a frustrating experience that you have had at the university and how you think your conversational partner might be able to advise you.

G. Respond to your conversational partner's description of costs and rewards.

H. Respond to your conversational partner's advice.

I. Based on your previous conversations you have had with your partner, request them to give you any advice you think would be helpful to you.

\section{Results}

Mentor and protégé communicative responses to the directives and to each other were read by the researchers and coded for their use of relational facilitation and maintenance strategies Although, this was a small sample, there was communicative support for the two propositions considered in this study.

The proposition that "protégés will be more likely than mentors to direct their conversational goals and communication strategies toward initiating, maintaining, and repairing their mentoring relationship," (Kalbfleisch, 2002, p. 67) was supported in that all five of the protégés sent messages to their mentors that not only sought advice but that were also directed toward initiating and maintaining their relationship. For example, in response to her mentor's advice, a protégé wrote:

I am glad that you have the opportunity to re-think your career and academic goals, it would be awful to be forced to live out a decision that you made before you worked in that particular field. Obtaining your $\mathrm{PhD}$ would be hard work, but it sounds like you are already on the right track. I couldn't agree more that working overseas would be a wonderful experience.

Another protégé wrote to her mentor that "I wish you the best in achieving your goals. There's nothing corny about working and studying hard to make your dreams come true. After all, without a little sweat and tears the final reward is never quite as sweet."

These messages are characteristic of the supportiveness and affirmation of messages sent by protégé's to their mentors. "I'm glad you have the opportunity ... "I couldn't agree more. .." "I wish you the best ..." all display positivity and warmth in their message content. 
The messages from the mentor were generally more task and self oriented rather than being focused on relational initiation and maintenance. For example one mentor wrote:

My worst frustration with the University involved having to take a class that I really didn't need. I did not believe I needed the class but the Registrar said I did. Instead of checking around more, I just went ahead and took the class. It wasn't until the end of the semester that I discovered I was right, I didn't need the class. I assumed that the people who do this every day knew what they were talking about. My recommendation and not just for school but everywhere is if in doubt ask around. Had I asked a couple professors, or talked to the head of that particular department I wouldn't have wasted my time and money on something I didn't need.

Another mentor, when asked for advice made the following posting:

I don't think you really need advice based on that specific experience. I think it's unfair for a teacher to tell a student they shouldn't be in college. If that's the case, they will find out on their own soon enough. Many freshmen don't come back the next year because of partying, bad grades, etc. But I think it's good to experience that (not to mention fun!) and you weren't ''weeded out' anyway. Teachers should try to support and encourage students, not put them down.

The second proposition considered in this study, that "female protégés will be more likely than male protégés to direct their conversational goals and communication strategies toward initiating, maintaining, and repairing their relationship with their mentor," (Kalbfleisch, 2002, p. 68) also received some support in this study. While all the protégés wrote more socially supportive messages than the mentors, this communication style was amplified with the three female protégés and subdued with the two male protégés. Compare this message from a male protégé with the previously described protégé messages, which were from female protégés:

I totally agree, teachers and profs are here to help us get though college not to put us down. The only real reward from college I think I received as I get closer to the end are friends, social skills, and a tolerance for work.

There is supportiveness in this message, but the level of relational maintenance exhibited in the female protégés messages is not as apparent.

In general the protégés and the mentors in this study expressed interest in this new format for mentoring because they felt it would allow them to be more honest and open than in a face-to-face context. Several of the participants had not previously been in mentoring relationships and this context allowed them to ask for help and provide assistance to others. Some of the messages about this technique of mentoring are illustrated in a protégé's posting that:

I have never really had any kind of mentoring relationship let alone one that was based over the internet. I do expect that it will give me an opportunity to learn from the experience of someone else and perhaps they can learn something from me as well. It should be interesting.

A mentor wrote:

I don't know what experiences you are looking for but I am full of them. I have worn many hats. I don't know that I have ever really had a protégé so I do not know what I am doing but I hope to learn something new everyday, and I would help to be able to pass something on that may help someone else's learning curve. One thing that I have learned and observed is that people are inconsistent, and that includes everyone, you, me, everybody. We may think that we are but we are not, not even the smartest most organized person in the world is consistent. This makes things difficult when it comes to situations with authority figures or the law but it is something to 
keep in mind. I don't know if this is a useful piece of information but it puts some perspective on life.

A protégé adds:

What I can bring to an online conversational relationship is just what I can offer to any other relationship I would enter into, my personal perspective, compassion, and hopefully a little humor. What I would like to achieve in an online mentoring relationship is to establish a safe and secure relationship where I can express my feelings and ask questions honestly without the fear of rid icule.

\section{Discussion}

\section{Internet Mentoring}

This study demonstrates that internet mentoring has promise as a vehicle for social support and personal and professional achievement. Research participants used this study to give and seek advice and to enter into mentoring relationships. Further, protégés attended to relationship initiation and maintenance in their messages, with the female protégés displaying messages that were even more supportive than the male protégés' messages.

This study lasted two and a half months and was comprised of five pairs of mentors and protégés. It was designed as a pilot study for a more extensive study that will incorporate more research participants and will more completely test the theoretical propositions proposed by Kalbfleisch (2002). The results from this study are limited but suggest support for the theory and for the viability and usefulness of mentoring relationships online.

\section{The Instrument}

One of the biggest challenges in this study had to do with the study instrument. The instrument, the forum discussion groups, was created using Microsoft FrontPage due to its ease of use. Although FrontPage automated a lot of the features of the forum discussion groups, it was through this automation that limitations were discovered. The major limitation was the inability to control functions on the FrontPage webbot designed to handle the discussion groups. The webbot handler was provided as a FrontPage extension located on the university's web server. The researchers did not have access to this webbot, nor did they have access to a list of commands used to control the functions on the webbot. Therefore it was difficult to determine if any of the features of the webbot could have been customized to fit the needs of the study. In an attempt to customize the webbot from the forum discussion pages, two of the discussion groups were rendered useless. After reverting the code on the webpage back to its original form, the webbot was still unable to perform its function for the discussion groups. The partic ipants of those particular groups had to be moved to a new discussion group under a new name.

Another limitation the researchers faced using Microsoft FrontPage was the inability to send email reminders to the participants. The participants requested that email reminders be sent as new postings were made. They expressed to the researchers that it would be easier for them to participate in the study with the email reminders. However, FrontPage's options only allowed for the posting from the forum discussion group to be directed either to the webbot or an email. It did not allow for both functions to be accessed as a new posting was made. In an attempt to solve this particular problem, the researchers considered placing scripting commands that would automate the email process. However, the researchers were also concerned that providing the participates' e-mails within the coding of the webpages would seriously compromise the confidentially of the participants. The concern was as follows: if a participant were to view the source of their forum discussion webpage, a relatively easy command found in all major web browsers, then they would easily have access to their conversational partner's email. An effec- 


\section{Facilitating Mentoring Relationships}

tive method for dealing with the email problem was discovered late in the study. It was discovered that the emails can be anonymously accessed by means of a protected database on the web server. Unfortunately, there was a small learning curve involved to implement the use of the database; therefore the time line of the study did not permit for the database to be implemented. Despite this limitation, the participants still requested email reminders to be sent to remind them of postings. Due to the lack of any automation in the study instrument, the researchers manually emailed each individual participant whe never a posting was made or a new directive was posted.

The final major limitation with the study instrument that the researchers faced was how the conversational directives were handled. FrontPage did not allow for automation of the conversational directives. The researchers had to manually check each forum discussion group several times a day to see if the conversational directive had been fulfilled. If the directive had been satisfactory fulfilled, then the researchers manually edited that particular group's discussion forum webpage to post the new conversational directive. After the new directive had been posted, the researchers then manually emailed the participants of that particular group informing them that a new directive had been posted. Even though the pilot study had only five conversational groups, the manual management of the conversational directives turned out to be an enormously time consuming process. The cumbersome task of manually maintaining the groups caused several additional problems. First of all, despite a well organized filing system, it became difficult to keep up-to-date tracks on which conversational directive each group was currently working on. There were a few instances where the participants were participating, but it was difficult to determine which directive they were working on. The format of the discussion forum group also allowed the participants to continue on threads from previous conversations. While it is was great that the participants were continuing a conversations, it proved to be cumbersome. A few of the participants focused their energies on maintaining their old conversation, instead of attending to their new conversational directives. Secondly, the researchers, being human, occasionally forgot to update the conversational directive, even though they had already sent out the emails informing the participants that the study had been updated. Although this error was always fixed in a timely manner, it most likely would have not occurred at all if a system of automation could have been implemented.

Finally, getting the participants to participate in the study proved to be more challenging than expected. The study was designed to be no more than three weeks in length. However, the participants were only half way through the conversational directives after two and a half months. A good majority of this problem could have been solved simply by automating the study. With the system of the researchers manually updating the conversational directives, the participant had to not only wait for their conversational partner to reply, but they also had to wait for the researchers to post the new directive. This may have caused the study time to be extended dramatically. Another problem the researchers faced was getting the participants started on time. A few of the participants provided inaccurate emails. These participants had to be tracked down to verify their email. This problem could have been solved if the emails were verified before the study had started. Unfortunately, for our study, these inaccurate emails simply caused more time delays.

Although it was suggested that the internet would be a valuable medium for mentoring, because the mentor and protégé could work on their own time, this did not prove to be the case in this pilot study. The participants were given plenty of time to participate in the study, yet there were several cases were days or weeks would go by without a posting. Although part of this problem is rooted in the design flaws of the instrument, the instrument itself cannot be a sole cause for a lack of participation by the participants. In some cases, they simply were not participating, despite the promised time advantages. Although this study alone does not provide enough evidence to debunk the claim that the internet provides time advantages to mentoring relationships, it does suggest that these time advantages of the internet may in fact not be an advantage. More research into the time issue will need to be conducted to see 
whether or not the internet provides an advantage in terms of time for a mentoring relationship. Perhaps this problem will be solved once the study is set up to be fully automated.

Throughout the course of this study, it was determined that a good majority of the problems encountered could have easily been solved simply by automating the study. The features that need automation are the email reminders and the updating of the conversational directives. Due to the enormous limitations found using Microsoft FrontPage's automated features, the study instrument is being redesigned without reference to any FrontPage extension (although FrontPage will still be used for the production and general maintenance). This should allow for more flexibility of features designed specifically for the study. Using ASP coding along with other scripting languages should allow the automations to occur. Also, ASP and the scripting languages will allow for use of a database, which can make the study run more smoothly. Despite these advantages, there is one major disadvantage to using ASP and the scripting languages. These languages have a higher learning curve than the automated features in FrontPage. Some computer science or programming background is needed in order to understand how to use these languages. However, once one has crossed this hurdle, the possibilities for developing future research projects in an online environment open up. The study reported in this article was designed as a pilot study for a follow up study utilizing a larger population. The problems with the FrontPage webbot should be averted using the new ASP system.

\section{Conclusion}

Are these Internet mentoring relationships real relationships? This study showed specific exa mples of protégé's relational maintenance strategies that are also used face-to-face in an online environment. This coincides with Walther and Burgoon's (1992) finding that relationships can develop in an online environment over time. Are they mentoring relationships? The initial data suggests that mentoring communication is present and can exist in an online facilitated environment.

The internet provides a key to mentoring relationship development that is not always available in a faceto-face context. That is that mentoring relationships can exist over time, over place, and without referent to physical features such as race, gender, and disability.

Through further development of internet software and programming abilities and through theoretical development and testing, the online mentoring environment may be fully realized as a valuable tool for the development of mentoring relationships and helping humankind achieve their dreams and full potential.

\section{References}

Adams-Price, C. E., \& Chandler, S. (2000). The star fleet ladies auxiliary: Evolution of an online women's mailing list. CyberPsychology \& Behavior, 3(5), 811-816.

Kalbfleisch, P. J. (2002). Communication in mentoring relationships: A theory for enactment. Communication Theory 12, 6369.

Kalbfleisch, P. J.(2000). Similarity and attraction in business and academic environments: Same and cross-sex mentoring relationships. Review of Business, 21(2), 58-61.

Kalbfleisch, P. J. (1997). Appeasing the mentor. Aggressive Behavior, 23, 389-403.

Kalbfleisch, P. J., \& Davies, A. B. (1993). An interpersonal model for participation in mentoring relationships. Western Journal of Communication, 57(4), 399-415.

Knouse, S. B. (2001). Virtual mentors: Mentoring on the internet. Journal of Employment Counseling, 38, $162-169$.

Merkle, E. R., \& Richardson, R. A. (2000). Digital dating and virtual relating: Conceptualizing computer mediating romantic relationships. Family Relations, 49, 187-192.

Parker, P. S. (in press). Control, resistance, and empowerment in raced, gendered, and classed work contexts: The case of African A merican women. In P. J. Kalbfleisch (Ed.). Communication Yearbook 27, Mahwah NJ: Lawrence Erlbaum Associates. 


\section{Facilitating Mentoring Relationships}

Pratt, L., Wiseman, R. L. (1999). Interrogative strategies and information exchange in computer-mediated communication. Communication Quarterly, 47(1), 46-66.

Walther, J. B. (1993). Impression development in computer-mediated interaction. Western Journal of Communication, 57(4), 381-398.

Walther, J. B., Burgoon, J. K. (1992). Relational communication in Computer-Mediated interaction. Human Communication Research, 19(1), 50-88.

Walther, J. B., Slovacek, C. L., Tidwell, L., C. (2001). Is a picture worth a thousand words?: Photographic images in longterm and short-term computer mediated communication. Communication Research, 28(1), 105-134.

Wolak, J., Mitchell, K. J., \& Finkelhor, D. (2002). Close online relationships in a national sample of adolescents. Adolescence, 37(147), 441-445.

Wright K. (1999). Computer-mediated support groups: An examination of relationships among social support, perceived stress, and coping strategies. Communication Quarterly, 47(4) 402-414.

Wright K. (2000). Computer-mediated social support, older adults, and coping. Journal of Communication, 50(3), 100-118. 